\title{
An Output-guided Study of Chinese Students' ESA Difficulty
}

\author{
Ting Zhang \\ English Department, Sichuan Agricultural University, Ya’an, China
}

\begin{abstract}
English subjunctive mood is always considered as the most difficult part of English teaching. English subjunctive mood carries specific grammatical features such as verbal inflexions, sentences structure, tenses and the understanding of counterfactual meaning. Swain $(1985,1995 \mathrm{a}, 1995 \mathrm{~b})$ poses Output Hypothesis to explain the difficulty of the $\mathrm{L} 2$ learners. Based on the hypothesis, pedagogical instructions are also provided theoretically. Other scholarly efforts such as Levelt $(1989)$ and Gass $(1988,1997)$ are also made to establish the models of SLA. Output Hypothesis is largely applied to a lot of empirical studies, but a specific framework is never found to explain and solve the ESA difficulty that Chinese college English majors have. The present research, on one hand, evaluates the models of SLA, on the other hand introduces Schema in cognitive linguistics to establish a framework that can explain and solve the ESA difficulty.
\end{abstract}

Index Terms - English subjunctive mood, SLA, output hypothesis

\section{INTRODUCTION}

English subjunctive mood is under academic arguments of whether it exists independently in English grammar or not. However, most scholarly studies believe it's existence. Traditional notion considers it as an inflexion of verb pattern in grammar, but cognitively it's a special conveyance of the counterfactual meaning, Chinese students have problem in the acquisition of English subjunctive mood ${ }^{1}$. Actually, according to some cognitive linguistic theories, English subjunctive mood is the superficial manifestation of an independent and special human thought process. Chinese students of course possess this common human cognition experience instinctively but problems will rise in their production of specific English subjunctive mood in verb transformation and sentence making.

This difficulty in acquisition must be analyzed based on two basic agreements: difficulty in the linguistic forms (grammar) and its cognitive mechanism. For example, from the perspective of transfer problem, Bloom (1981) has conducted some interesting but controversial studies on the differences between how Chinese and English speakers reason. Bloom insists that since the Chinese language does not explicitly mark the counterfactual, Chinese speakers would experience greater difficulties with counterfactual reasoning. Bloom concluded that the presence or absence of explicit marking of the counterfactual in one's language influences the facility with which one uses this mode of thought. From the cognitive perspective, in human cognition system, besides fundamental category, the cognition of relationship among things constructs another important cognitive structure. Lakoff (1987) names it as "kinesthetic image schema". Kinesthetic image schema is the cognitive structure based on the cognition of relationship among things, higher than fundamental categorization, which connects things in human comprehension and experience. The structure is an organization of repeated knowledge, in order to comprehend more complex concepts. Human experience and knowledge are constructed through the structure.

From the examples listed above, we can find that English subjunctive mood acquisition (ESA) occurs to be a problem to Chinese students. The analysis of the SLA of Chinese students may help the acquisition of the subjunctive mood. The factors involved are the acquisition process and the methods applied in the teaching and learning. When we talk about teaching and learning, the best way to find out the real problem in the acquisition is by carrying out an empirical study which involves the specific data to enable us to research a pattern, according to which the development of ESA is made. This thesis includes the empirical study conducted by a model from evaluating and inheriting Swain's output hypothesis and the other SLA researches. By applying the experiments, the factors involved in ESA are defined and studied. Solution to the problem is suggested according to the analysis of the data collected from the students tested in Zhang Ting's experiment and then obtained for the study.

Primarily, the objective of the study is to define the problem in Chinese students ESA and to provide a possible solution to it according to the relevant theories and hypotheses, as is claimed above.

As an empirical study, the objective of this research is also to testify the framework inspired by SLA theories and cognitive approaches through an experiment.

Volunteers' performance in the experiment is measured, observed and then they are trained in the experiment. Data are collected through the preset experimental procedure. The first-hand data are collected and analyzed, afterwards, conclusion is made through the result analysis.

${ }^{1}$ The acquisition of English subjunctive is shortened as ESA 
In the experiment, subjects are randomly chosen. Data will be collected in designed diagrams and will be contrasted and analyzed to find any difference which will show the defining factors of Chinese students' English subjunctive mood acquisition.

Being a quantitative and inductive research, the model of illustration in the literature is testified after the analysis of the data bank.

This research tends to find out the different problems in the acquisition by analyzing the acquisition difficulty of English subjunctive mood among Chinese students and application of the relevant cognitive theories which are believed to reveal the reason of the difficulty. The theoretical frame of the present study is inspired by Swain's (1995) Output Hypothesis, Gass's (1988) model, and Levelt's (1989, 1992)production model. In the evaluation of these models and the application of these models and theories by other researchers, a framework is established to analyze the result of the empirical study. To be specific, various theories such as Bloom's description of transfer, Swain's output hypothesis, Gass' output model and other researchers' reflections are referred to. These hypotheses are utilized to analyze in the empirical study the difficulty of ESA in terms of linguistic forms. Cognitive hypotheses such as 'Kinesthetic Schema' are used to further explain the cognitive reason for the mechanism of the difficulty.

Swain's output hypothesis (1995) holds that learners of a second language are in need of the chances for the pragmatic use of their linguistic database. Swain calls such meaningful use of the target language 'pushed language use.' According to her, the output practice has at least three functions: (1) Output encourages hypothesis testing; (2) Output facilitates the metalinguistic development, i.e., the learning of various rules about L2 and L2 use. (3) Output contributes to consciousness-raising. In the input practice, i.e., listening or reading, Swain argues, learners are engaged in semantic processing, i.e., making meaning out of text, which does not necessarily lead to the development of syntactic competence. Only the output practice forces them to move from semantic to syntactic processing. Gass (1988) also provides a model in which output is paid great attention to. She suggests the explicit knowledge as a kind of "storage", which can contribute to output through monitoring... Output can influence input through interaction. Besides, Levelt's production model $(1989,1992)$ also does some value to the present study, for in the model, there are "conceptualizer" and "formulator" out of five of his model's ingredients.

Moreover this acquisition process is from controlled process to automatic process. McLaughlin (1983) poses the 'Information Processing Model'. He explains SLA with the notions such as 'controlled processing', 'reconstruction of interlanguage'. In his model, learners employ controlled processing when starting learning, in this process, learners select information from temporary memory with greater cognitive effort. With the development of learning, controlled processing shifts to auto-processing, then the auto program is stored in permanent memory. Brown (1994) attempts to use McLaughlin's model on the explanation of various aspects of SLA, for instance, controlled processing includes new techniques such as specific grammar, word meaning, spelling, sentence structure etc., while auto-processing includes familiar techniques such as self-correction in writing and speaking, compositionality of sentences etc.

Besides, other accounts hinted by other disciplines are briefly viewed and considered in the chapter of literature review.

\section{About English SubJunCtive MoOd AND SLA IsSuES}

\section{A. Introduction}

To define English subjunctive mood, "the first thing is to make clear the definitions of "tense' and "mood". (Jespersen, 1905) Quirk wrote in A Grammar of Contemporary English (1972, p. 84), "English has two tenses: Present Tense and Past Tense. AS the names imply, the Present Tense normally refers to present time and past tense to past time." In his 1985's A Comprehensive Grammar of the English Language, he claimed that as most commonly used, the Past Tense combines two features of meaning: (a) The event/state must have taken place in the past or (b) The speaker or writer must have in mind a definite time at which the event/state took place (Quirk, 1985).

Mood is a set of contrasts that are often shown by the form of the verb and which express the speaker's or writer's attitude to what is said or written. (Jack C. Richard et al, 2000, p. 295). Three moods are sorted out by traditional view of English grammar: the indicative, the subjunctive mood and the imperative. The indicative mood is used when speaker considers the action or state denoted by the predicate as a fact. It is used in statements of fact either affirmative or negative, and also in questions and exclamations of facts. The indicative mood, as a common sense, occurs in Modern English sentences most frequently. Comparatively, subjunctive mood was more frequently used in Old English and Middle English. The subjunctive mood has been declining in Modern English now.

The terminology "subjunctive" is derived from the Latin terminology "subjunctivus", meaning "proper to be subjoined". (see Sun Hongren, 1999) So, in subordinate sentences, we see more subjunctive mood use. Nowadays, since many English subjunctive inflexions have gradually disappeared, the use of the mood is less and less. Quirk (1972) said: "The subjunctive is not an important category in contemporary English and is normally replaced by other constructions. In fact, both the indicative and the subjunctive forms are available for hypothetical conditionals, the subjunctive being preferred in formal written English."

Now we can see that English subjunctive mood is a verb pattern more likely occurring in English subordinates and is used to express hypothetical and counterfactual matters. 


\section{B. English Subjunctive Mood in Terms of Pedagogy}

Zhang Daozhen (2002) classifies English subjunctive mood into three kinds, according to the verb forms: the present, the past, and the past perfect. However, traditional view is the division of "the present" and "the past". However, the specific indicators of English subjunctive mood can be referred in Zhang Daozhen's description (2002).

The most important and frequent indication of subjunctive mood in English structure is in conditionalscounterfactual conditionals. The present and future counterfactual conditionals have the verb form as the past tense in the subordinates and the "would + do" structure in the matrixes. The past counterfactual conditionals have the verb form as the past-perfect tense in the subordinates and the "would have + done" structure in the matrixes.

Mixed time counterfactual conditionals are possible when the verbs in subordinates and the matrixes take their own grammatically-legal forms respectively. There are also implied conditionals. They may not have subordinates but the semantic feature is the same-conditionality.

English subjunctive mood is also used in some types of subordinates:

1) The verbs wish/ would rather/ suggest (demand/ insist/ ask) etc. ask for correspondent verb forms to indicate subjunctive meaning in the objective subordinates. For example (Zhang Daozhen, 2002):

a. I wish I knew what was going to happen.

b. I'd rather you told me the truth.

c. He suggested that a petition (should) be drawn up.

2) Certain adjectives and nouns, especially the nouns and adjectives (participles) derived form such verbs like suggest/ demand/ insist/ ask etc. require the subordinates with subjunctive mood. Here are the examples (Zhang Daozhen, 2002):

d. It is important that he work hard.

e. My suggestion is that we take the 6:00 train.

f. There have been demands that the prime minister should resign.

3) In certain kinds of the adverbials, English subjunctive mood is used; here are the examples (Zhang Daozhen, 2002):

g. I have loved you as iflas though you were my son.

h. Though he be the President himself, he shall hear us.

i. Come what may, we will go ahead with our plan.

$\mathrm{j}$. They moved the prisoner in order that he not disturb the proceedings any further.

$\mathrm{k}$. I hired a boat so that I could go fishing.

1. I'm surprised that you should press the suggestion.

4) The other indications (Zhang Daozhen, 2002):

$\mathrm{m}$. God be praised! (Greeting words)

n. May you enjoy many years of health and happiness. (Greeting words)

o. It's (high) time you brought a new car.

p. Oh that the rain would stop!

q. Would that he were gone!

r. To think that I trusted him!

s. He is, as it were, a walking dictionary.

t. Who would have thought to see you here!

u. I can earn my own living if need be.

(The relevant example sentences above are quoted from Zhang Daozhen, 2002.)

Traditional grammarians believe that English subjunctive is an important and valuable component of English language; it's not likely to be disappearing with the increase of tenses. For example, L.M.Berk (1999) said: "Like the term 'imperative', the term 'subjunctive' refers to a particular verb form...The subjunctive is somewhat weak in Modern English, but there are speakers who use it routinely. In many cases, the subjunctive is a form learned in school or through reading, so it is educated speakers who use it most. The modern subjunctive expresses a variety of denotic meanings (Here, denotic refers to a sense of duty or obligation of something which is required or desired)." According to the description above, it is very clear that though the subjunctive mood has a tendency to be more ambiguous in the present English language, it is considered being existing in the language as an important grammatical phenomenon. It is seldom used but it is not vanishing and is still worth being defined as one independent existence in English language.

Some grammarians think that English subjunctive mood is vanishing because "While the number of tenses has been increased, the number of moods has tended to diminish, the subjunctive having now very little vital power left." (Jespersen, 1905) H. W. Fowler (1926, p. 57) wrote in his A Dictionary of Modern English Usage: "About the subjunctive, so delimited, the important general facts are: (1) that is moribund except in a few easily specified uses, (2) that, owing to the capricious influence of the much analyzed classical upon the less studied native moods, it probably never would have been possible to draw up a satisfactory table of the English subjunctive uses, (3) that, assuredly noone will ever find it possible or worthwhile now that the subjunctive is dying, (4) that subjunctive met with today, outside the few truly living uses, are either deliberate revivals by poets for legitimate enough archaic effect or antiquated survivals as in pretentious journalism, infecting their context with dullness, or new arrivals possible only in 
an age to which the grammar of the subjunctive is no natural but artificial." Palmer (1974, p. 48) said in his The English Verb: "Traditional grammarians would object that the unreality use is essentially the subjunctive, but the notion of a subjunctive mood is a simple transfer from Latin and has no place in English grammar, since all the potential subjunctives turn out to be past tense in form (or to be the simple uninflected form as in 'God save the Queen').

Some hold a neutral idea that there is the subjunctive mood in Modern English but it is not very important. As Quirk (1985)wrote in A Comprehensive Grammar of the English Language: "the subjunctive in Modern English is generally an optional and stylistically somewhat marked variant of other constructions, but it is not so unimportant as sometimes suggested." And he has classified it: "There are two forms of the subjunctive, traditionally called the present and past subjunctive, although the use of these forms relates more to mood than to tense." To give English subjunctive a fairly independent property from the indicative, Quirk (1972) asserted that both the indicative and the subjunctive forms are possible for hypothetical conditions, the subjunctive being preferred in formal written English.

\section{The Difficulty in Acquiring English Verbal Inflexions}

English subjunctive mood is in the forms of verbal inflexions which lead to Chinese students' problem in learning to use it.

Contrary to any normal L1 child, who can obtain a full knowledge of the language of the community in which they live at age of five, L2 learners will encounter a great deal of difficulty in acquiring L2 and most learners will generally fail to attain native-like competence. The same is true of Chinese learners of English. It is observed that Chinese learners of English have great difficulty in acquiring English especially in acquiring English verbal inflexions. These inflexions are used to indicate agreement, tense, etc, and they are notoriously difficult to acquire for non-native speakers. The meanings and forms of tense are difficult and complex to acquire for non-native speakers. (Hinkel, 1992 \& 1997). Givon (1993) also states that the grammatical point of verbal inflexions is usually the most complicated part of the grammar in any language. As McCarthy (1991) put it, tenses are a "traditional stumbling-block" and can certainly be difficult to acquire. Compared with non-native speakers, children are quick to acquire the grammar of L1. The classical explanation of children's ease of acquiring the grammar of L1 is put forward by Chomsky: "A consider of the character of the grammar that is acquired, the degenerate quality and narrowly limited extent of the available data, the striking uniformity of the resulting grammars, and their independence of intelligence, motivation and emotional state, over a wide range of variation, leave little hope that much of structure of language can be learned by an organism initially uniformed as to its general character." (Chomsky, 1965, p. 58)

The gap between the language attainment and the available language experience for L1 acquirers is known as the logic problem. Universal Grammar (UG) is the innate language mechanism that bridges the gap by helping the lan guage acquirers to know unconsciously "interiorization" of the grammar that are far from the input in various respects. Though there is much debate over the three logical possibilities that describe the role of UG in SLA, namely, "no-access hypothesis" which means there is not any perspective of UG applied to the L2 learner; "partial access hypothesis" which means only L1-instantiated rules and L1-instantiated function of UG are useful to the learner; and "full access hypothesis" which means UG in its entirety defines L2 acquisition, the function of UG in L2 acquisition is still unclear. However, one thing for sure is that L2 learners do have great difficulty in acquiring L2.

Moreover, English and Chinese are two radically different languages, which possess different subsystems to express tenses and aspects. English marks verbs in two dimensions: (a) tense: "the location of an event in time" (Comire, 1985) and (b) aspect: "ways of viewing the temporal constituency of a situation." On the other hand, Chinese is thought of as a "tenseless" language whose temporal location is expressed directly by adverbials and indirectly by the use of aspectual viewpoint. Apart from the above problems, most Chinese learners of English acquire English verbal inflexions in L2 classrooms by presenting rules, explaining the meaning of tense and by practicing. Therefore, learners are badly short of real L2 environment. Due to the lack of language environment and the radical difference between English and Chinese, it is not surprising that we, Chinese learners of English, have a great deal of difficulty in mastering English verbal inflexions.

\section{SLA ISSUES VIEWED FROM OUTPUT HYPOTHESIS}

Krashen's (1985) input hypothesis intends to answer a critical problem in SLA, that is: how do humans master a language. His proposal claims that language is produced by accepting a large amount of Comprehensible Input (CI). Perceivable materials, as listening and reading materials are the critical factors in SLA. And according to Krashen's " $i+1$ " notion, the perceivable lingual materials must be higher in level than the learner's already-acquired linguistic knowledge. Krashen also (1985) posed two inferences: a) "Production" is the result of acquisition. Production is acquired through considerable "comprehensible input". b) Learners can have right syntactic forms after being "input" a lot. In all, we can infer from Krashen's hypothesis, "input" is the decisive aspect of successful SLA.

Meanwhile, Swain (1985) had looked into Canadian's immersion program of French teaching. The research showed that the students had highly improved their listening and reading capabilities but in "production"-speaking and writing - they had failed to reach the target language's (TL) standard, and done poorly in producing correct syntactic forms. Swain (1985) then asserted that Comprehensible Output (CO) is more important and critical in SLA. Swain's output hypothesis holds that output has four functions: 1) noticing/triggering function, which means learners pay more 
attention to their language through output; 2) hypothesis testing, examining TL's structure and semantics; 3) metalinguistic function, which learners utilize to express; 4) developing automaticity, TL can be automatic through "output". Swain \& Lapkin (1995) found that noticing triggers learners' inner cognition about SLA. Some other researchers find learners modify their language by testing and are pushed to develop new interlanguage which is gradually modified to meet TL's standard. (Pica et al, 1989)

In contrast with these two hypotheses and relating to English subjunctive mood's property we can see that as a verbinflexion-featured language phenomenon, English subjunctive mood is hard for Chinese students, whose mother language is inflexion-free. Lots of "comprehensible input" may make Chinese students better in comprehension of counterfactual meaning but output can better improve their master of the complex verb-pattern in the production of subjunctive mood structures in their actual language performance.

In second language acquisition research, output has long been assigned to a passive role. For many researchers and language teachers, output is just the manifestation of the acquired knowledge and plays no facilitative role in language teaching. Gass (1997) summarizes the traditional views on output in her book named Input, Interaction, and the Second Language Learner.

According to Gass, the first traditional view on output is that it is not a way of creating knowledge, but a way of practicing already-existing knowledge. In other words, output has been viewed as the means of practicing what has previously been learned. This point of view is clearly manifested in the following figure presented by Vanpatten and Cadierno (1993, p. 227)

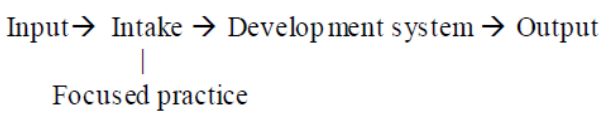

Figure1: Traditional instruction in foreign language teaching, by Vanpatten and Cadierno

The figure demonstrates the traditional teaching method in foreign language teaching. As is known to all, in the traditional foreign language classroom, teachers' instruction appears by first explaining a language presentation and then making students practice repeating a given structure or form. In this figure, it can be seen that the arrows go from left to right not the reverse. Output is considered to be the result of the developing system, but not the cause of it. It seems to have no role to play in developing the learners' interlanguage. Output and the manipulation of output are viewed just as a forum for practicing rules that have been presented to learners. This is certainly the thrust behind the early methods of language teaching in which the presentation-practice (for example, drill and repetition) mode was in vogue.

The second traditional view on output is that it is a method of eliciting additional input. The representative figure holding this view is Krashen. According to Krashen's Input Hypothesis, learners can proceed according to the natural order by accumulating input that contains the structure at their next stage; the structure that is a bit beyond their current level of competence. Krashen claims: "we acquire a language via input, what we read and hear, not via output, actual talking and writing" (1982, p. 57). Krashen acknowledges that output makes a positive effect on language acquisition, but this contribution is not a direct one. Through practicing output, learners can elicit more and better comprehensible input, thus facilitating language acquisition. Output affects the quantity of input a language learner receives, because the more he talks, the more people will talk to him. Output also affects the quality of input language learners receive, because oral dialogue practice group members often try to help learners understand by reminding them of their wrongs in their speech. They judge how to help revise by observing if what is said is comprehended, and also by listening to the conversers' talk. A second language speaker, who makes a lot of mistakes, has a bad original accent and is not fluent, will most likely to receive, in general, more revised "right" imbueing than a speaker who appears confident and smooth. Long (1983) has the similar opinion. He believes that second language learners can only get good quality input by using output (speaking) to give the interlocutor feedback, so that the input directed to them is more finely tuned to their current competence.

From the above paragraphs, it can be seen that for many researchers and language teachers, output is just an indication of SLA that has already taken place, and it seems to have no role to play in SLA except as one way of practicing already-existing knowledge for greater fluency or as the means of eliciting additional input. It is an yield of learning, not an origin of learning. These traditional views on output were not challenged until 1985, when the Output Hypothesis was first proposed by Swain. In this hypothesis, Swain claims that output serves SLA in several ways. It is also an important causal factor in language learning process. In order to achieve native-like proficiency, both comprehensible input and comprehensible output are needed. Output also plays important roles in advancing language learning.

Swain's Output Hypothesis is formulated essentially in reaction to Krashen's Input Hypothesis and is based on many years of research on Canadian immersion programs.

Just as mentioned above, Krashen views input as an essential environmental ingredient for second language acquisition. He states: "human beings acquire language in only one way-by understanding messages or by receiving "comprehensible input" (1985, p. 2). As is said, language acquisition is decided by focusing on comprehending what others are giving out. Provided that the learner hears meaningful speech and endeavors to understand it, acquisition will 
automatically occur. "If input is understood, there is enough of it. The necessary grammar is automatically provided." (Krashen, 1985, p. 3). As for output, Krashen de-emphasizes its utility. Krashen regards it as a result of acquisition not its cause. Krashen claims: "speaking will 'emerge' on its own as a result of building competence via comprehensible input” (1985, p. 2). In Krashen's opinion, the active knowledge of how to use a second language never benefits from outputting the knowledge of a language. Its only positive effect may be that it involves other people into speaking, thus offering more objects for the learner to deal with. Krashen even declares: "it is, in fact, theoretically possible to acquire language without even talking" (1982, p. 66). This emphasis on input at the expense of output is a distinguishable feature of Krashen's theory. Krashen's points of view are quite influential within second language education and have had considerable impact on the nature of pedagogical provision.

Krashen cites many evidences to support his Input Hypothesis, one of which is the success of immersion programs. Immersion programs refer to the educational programs where the teaching of language is integrated with content teaching. In these programs the students receive a substantial portion of their education via the medium of their second language. The goals of these immersion educations include both academic achievement in the content areas studied and a high level of proficiency in the second language. After many years of study in these programs, the students there do realize the goals. They do achieve great progress both in their content learning and language learning. Researchers, such as Swain (1981) and Allen et al (1982), have conducted a series of research in a number of French immersion programs across Canada. By comparing the students in the immersion programs with those in the regular programs, they find that the immersion students do as well as others in the subjects such as mathematics, science, history and geography. Besides achievement in their content learning, they have made great progress in many areas of their language development. For example, they have developed a remarkable ability to comprehend oral and written discourse. They are quite fluent in using the TL. Their functional ability and confidence in using the TL are also greatly enhanced. In Krashen's estimation, “Canadian immersion is not simply another successful language teaching program-it may be the most successful program ever recorded in the professional language teaching literature" (Krashen, 1984, p. 61). Krashen believes the success of immersion programs resides in the fact that the students there receive a plenty material of understanding input. For example, the subject-matter material in these immersion programs is made easy to understand to involving students in several ways. The segregation of native speakers helps guarantee that teachers will speak at a language level available in conveying meaning to the students.

It is true that these immersion students have achieved great success in their second language learning, but it does not mean these programs are perfect. They still suffer from drawbacks. Harley (1983) and Swain (1983, 1984) find that the immersion students are still clearly distinguishable as foreign speakers and writers despite a vast amount of comprehensible input they have received. They evidence less understanding and master of complex grammar, less right judgement on their general use of vocabulary and morphosyntax. Although there is continued progress through the grades, their interlanguage remains sufficiently 'off-target' as to be a cause of concern. Considering Krashen's comment that "if input is understood, and there is enough of it" (Krashen 1985, p. 2) and "the necessary grammar is automatically provided" (Krashen, 1985, p. 2), these results are unexpected. Facing this situation, Swain argues these results may indicate that Krashen's Input Hypothesis needs refinement. The simple provision of meaningful input which is comprehensible to learners, while clearly necessary, is not itself enough for learners to fully develop their L2 competence. Now what is responsible for the weakness in these immersion programs? According to Swain, one of the important reasons for this is that these learners engage in too little language production, which prevents them from going beyond a functional level of L2 proficiency. Immersion students, Swain (1985, p. 249) argues, lack opportunities for output in two ways-

"First, the students are simply not given-especially in later grades-adequate opportunities to use the target language in the classroom context. Second, they are not being "pushed" in their output. That's to say, the immersion students have developed, in the early grades, strategies for getting their meaning across which are adequate for the situation they find themselves in: they are understood by their teachers and peers. There appears to be little social or cognitive pressure to produce language that reflects more appropriately or precisely their intended meaning: there is no push to be more comprehensible than they already are. "(Swain, 1985)

Experimental studies of interactive behavior in French immersion classroom have indicated that immersion classes are largely teacher-centered. The teachers do most of talking while students do much of listening. The students are not required to give extended answers and few of the students' utterances are longer than a single clause (Allen, Swain, Harley \& Cummings, 1990; Swain, 1985). This allows students to manage successfully with their incomplete recognition of the language; communication among students and between teachers and students is quite encouraging despite lots of mistakes in the students' speech. Observations such as these have led Swain to the conclusion that understanding target language utterance is not enough and the learners must also be given the adequate opportunities to produce them. What the students need is not only comprehensible input but also comprehensible output. Both of them are the necessary conditions for successful language learning. "By comprehensible output is meant that the learner is pushed toward the delivery of a message that is not only conveyed, but that is conveyed accurately, coherently, and appropriately." (Swain \& Lapkin, 1989, p. 156) Comprehensible output has its unique roles to play in SLA. It must be considered not just a sign of acquired knowledge, but also a sign of learning at work. 
Its role is, at minimum, to provide opportunities for contextualized, meaningful use, to test hypothesis about the target language, and to move the learner from a purely semantic analysis of language to a syntactic analysis of it (Swain, 1985, p. 252)

In 1985, Swain puts forward a hypothesis relevant to the L2 learner's presentation compared to Krashen's Comprehensible Input Hypothesis. This hypothesis is termed 'Comprehensible Output Hypothesis'. This basic presupposition of the Comprehensible Output Hypothesis declares that producing the second language, especially when learners have difficulties in conveying their attempted meaning successfully, forces learners to make their output more precise, fluent, and decent and that this process contributes to second language acquisition.

Swain $(1993,1995)$ extends the scope of the hypothesis and identifies the following four functions of output.

First, output develops the fluent and automatic processing. This function is called the fluency function, which is quite familiar to us. In order to develop a speedy access to the extant second language knowledge for fluent output performance, the students need many chances to use their accumulation in meaningful texts/conversations, and this naturally depends on output. Output provides opportunities for effective practice of one's linguistic database, permitting the development of automaticity in their use.

Second, output has a metalinguistic function, or what might be referred to as its 'reflective' role (Swain, 1995, p. 128). It is claimed that

"as learners reflect upon their own target language use, their output serves a metalinguistic function, enabling them to control and internalize linguistic knowledge" (Swain, 1995, p. 126).

In other words, output may cause the learners to engage in more syntactic processing than is necessary for the comprehension of input. This syntactic processing may lead to modified or reprocessed output — a possible step toward language acquisition. Reflection on language may not necessarily involve metalinguistic terminology. 'Meta-talk' produced with or without metalinguistic terminology may, according to Swain, serve the function of deepening the students' awareness of forms, rules, and form-function relationships, provided that the context is such that the language produced by the learners serves some genuine communicative function.

Third, output has a hypothesis-testing function. That is, producing output is one way of testing one's hypothesis about the target language - to try out means of expression and see if they work. Researchers have found that learners from hypotheses about the structural properties of the target language on the basis of the input data to which they are exposed (eg. Mclaughlin, 1987, 1990: Selinker, 1972). Ellis (1994, p. 352) argues that these hypotheses can then be tested receptively and productively. Hypotheses are tested receptively by means of listening \& reading and productively by means of speaking \& writing. . Listening and reading provide more input material, which enables the learners to confirm, reject, or modify his or her existing hypotheses about the target language. Hypotheses can also be tested productively. Production involves a series of learner-generated hypotheses and assumptions about the second language (Swain, 1995, 1997). It represents the learners' best guesses about how the target language works. When learners' guesses are tested, they are either confirmed or rejected/disconfirmed. Hypotheses are confirmed if the learners successfully transmit the intended meaning of the message successfully. Hypotheses are disconfirmed (rejected) and revised if the learner's output fails to communicate the intended meaning of the learner's message successfully (Ellis, 1994, p. 352). Therefore, through producing the target language learners can test comprehensibility and linguistic wellformedness of their interlanguage against feedback obtained from their interlocutors.

Finally, output gives rise to noticing. It is called the noticing/triggering (or consciousness-raising) function. This function of output is the focus of the present thesis. By the noticing function, Swain (1995, p. 125-126) postulates: "In producing the target language (vocally or sub-vocally), learners may notice a gap between what they want to say and what they can say, leading them to recognizing what they do not know or know only practically. In other words, under some circumstances, the activity of producing the target language may prompt second language learners to consciously recognize some of their linguistic problems; it may bring to their attention something they need to discover about their L2."

Swain believes that output forces learners to move from semantic processing prevalent in comprehension to syntactic processing needed for production. In production, the learners are on their own and they cannot rely on external clues and background knowledge in the same way as they do in comprehension. To produce, they need to be more active: They need to create communicative intentions and express them in linguistic forms; in doing so they may notice their linguistic deficiency. Researchers studying the communication strategies do find that learns notice problems when they speak (e.g., Tarone, 1997; Bialystok, 1990; Kellerman, 1991). Of course, noticing a problem does not equal solving it, but the awareness of a problem can give learners the incentive. In order to solve their linguistic deficiency, learners may try ways that are appropriate in a given context. For example, if the learners are left on their own to solve the immediate production difficulty, they may search their own linguistic knowledge for information that might help to close the gap by generating new knowledge or consolidating existing knowledge (Swain \& Lapkin, 1995). On the other hand, if relevant input is immediately effective, the strengthened sense of problem-causing during output may cause students to deal with the ongoing input with more focused attention. They may try to examine closely how the target language expresses the intention that they just had difficulty in expressing on their own. In either case, learning is believed to be enhanced through the act of producing language, which, by its mechanisms, makes learners more aware of their linguistic problems, which leads to reappraisal of their inter-language capabilities. 
From the above paragraphs, it can be seen that output plays several important roles in language learning. The traditional viewpoints on output should be changed. Output is not only a result of second language acquisition, but also an important causal factor in learning a language. It has its own unique contributions to learning processes. Two points need to be mentioned here. First, the Output Hypothesis is not the terminator of the Input Hypothesis. It tends to complement and reinforce rather than replace input-based approaches to language acquisition. Swain also acknowledges the importance of input or input comprehension. What she wants to emphasize is that output also plays an active role in second language acquisition. Producing the target language has the advantages that are not processed by comprehension. Second, simply providing students with opportunities for output is not enough. Swain (1993) claims that the learners not only need the opportunities of output but also need the opportunities of 'pushed output'. In order to bring the functions of output into play, learners need to be pushed to make use of their linguistic resources.

The Output Hypothesis can help to examine how Chinese students can acquire the specific linguistic forms (verbal inflexions, subjunctive forms) and to promote their grasping of the form.

\section{MODELS OF ACQUisition}

This research analyzes Levelt's (1989) and Gass's model (1988), and views as a three-step process, as follows:

1. Input level includes 'apperceived input' and 'comprehended input'. In this level, selections are made by learners and a great deal of cognitive effort is made.

2. Knowledge level is the level of 'intake', in which input is split into 'explicit knowledge' and 'implicit knowledge'. Furthermore, since implicit knowledge generates output, controlled processing is also turned to auto-processing in this phase.

3, Output level, the actual utterance is produced. The production is generated by auto-processing, so output should be enforced to promote SLA.

Moreover, the connections of the three levels involve cognitive processing, too, not only the transition from controlled processing to auto-processing.

Firstly, between level 1 and level 2, schematization is involved in the selection. For example, the forms happening in L2 but not in L1 are supposed to be selected by learners to build up new schemata. Secondly, between level 2 and level 3 , schematization also happens and is facilitated for output with auto-processing. The significance of my framework, to be assumed, is the explanation on how the levels are connected by schematization. (Table 2.2)

\begin{tabular}{|c|c|c|c|c|}
\hline Levels & Contents & Cognitive process & mechanism & Connection \\
\hline Input level & $\begin{array}{l}\text { 1.apperceived input } \\
\text { 2.comprehended input }\end{array}$ & $\begin{array}{l}\text { selection among the } \\
\text { information from temporary } \\
\text { memory }\end{array}$ & & \multirow{2}{*}{$\begin{array}{l}\text { building new } \\
\text { schemata of L2 } \\
\text { features }\end{array}$} \\
\hline \multirow[b]{2}{*}{ Knowledge level } & Intake, with the varieties & schemata are expressed to be & transmission from & \\
\hline & $\begin{array}{l}\text { of implicit knowledge } \\
\text { and explicit knowledge }\end{array}$ & $\begin{array}{l}\text { explicit knowledge and is } \\
\text { mentally operated to be } \\
\text { implicit knowledge }\end{array}$ & $\begin{array}{l}\text { controlled processing } \\
\text { to auto-processing }\end{array}$ & \multirow{2}{*}{$\begin{array}{l}\text { facilitate the } \\
\text { schemata and form } \\
\text { permanent memory }\end{array}$} \\
\hline Output level & L2 Output & $\begin{array}{l}\text { auto-processing guided } \\
\text { output }\end{array}$ & & \\
\hline
\end{tabular}

Output of the learners can help facilitate the schemata to form permanent memory. Let's begin to analyze this with the three types of schema.

James (1979) suggests that there be basically three areas of schema or prior knowledge structure that play a part in the act of listening or reading comprehension, namely linguistic schema (language knowledge), content schema (topic knowledge) and formal schema (rhetoric knowledge).

Linguistic schema is the knowledge of letters, sounds, grammar, syntax and vocabulary. Carrell and Eisterhold stated (1983) that linguistic schemata include the aspects of basic linguistic knowledge such as pnoetics, lexis, grammar and so on. Above is the content schema, which refers to people's background knowledge of the world. It is the basis for comprehension. It deals with the knowledge relative to the content domain of the text. Turner (1994) says that the information contained in context schemata includes predictions about appropriate actions to take in order to achieve goals in context, and suggestions for reasonable problem-solving strategies. Johnson (1982) has noticed that a text on a familiar topic with background knowledge is better recalled by English foreign students than an unfamiliar topic. Formal schema is the third type. It is the background knowledge of the formal rhetorical organization structures of different types of texts. (Carrell and Eisterhold, 1983)

In this research, content schema and formal schema are very important. The schemata established in students' minds are the key to ESA. That Output can help to consolidate the learner's linguistic knowledge is because their schemata are established through the process.

Output hypothesis explains that the acquisition of language is mainly decided by the output of the learner and schema can explain why it works well.

The model has three levels and these levels and the cognitive mechanism involved are testified and proved by the empirical study statistics. We can see it respectively: 
1. Input level includes 'apperceived input' and 'comprehended input'. In this level, selections are made by learners and a great deal of cognitive effort is made. When instructed by the teacher with the grammar rules, the participants firstly notice the rules in their explicit expression. For example, the verb "wish" needs its objective clause apply the past form of the predicate if the whole sentence is present tense.

2. Knowledge level is the level of 'intake', in which input is split into 'explicit knowledge' and 'implicit knowledge'. Furthermore, since implicit knowledge generates output, controlled processing is also turned to auto-processing in this phase. In processing the knowledge they receive from the teacher, the participants use the multiple choice as a measurement. They begin to analyze the purpose of the questions in the quizzes, and progress is made rapidly. At the same time, some participants have developed the ability to make sentences in English subjunctive mood and evaluate the subjunctive meaning in translation while attempting to use the right form in their writing. It is very instructive that the participants who are encouraged to express and practice what they have learnt (G3) make more rapid progress than those who are only imbued with the knowledge without any chance to practice under instruction $(\mathrm{G} 2)$.

3, Output level, the actual utterance is produced. The production is generated by auto-processing, so output should be enforced to promote SLA.

This level involves the schematization. The participants have set up the schema of ESA and automatic response can be made when conveying and comprehending the subjunctive meaning. Right forms are used easily and automatically. G3's performance is more significant, which proves that more out-put is more beneficial in ESA.

In the teaching and leaning of English subjunctive mood, the model introduced, analyzed and proved in the latter part of this thesis can have some positive guidance.

First, teachers should encourage students to practice what they have learnt but not just list out the knowledge of the grammar for the students to remember. According to the criticism against the mere-input methodology, the simple exposure to the knowledge but without any practice to reinforce it would not evidently and permanently improve SLA (including ESA).

Next, students should utilize any chance to practice what they have received from the teacher and class, try not only to remember the points and descriptions of the rules but also write and utter the actual words with constant revision of the errors. Gradually, the knowledge is internalized and turned into the automatic response when one is using the linguistic structures.

This research is also limited in its theoretical analysis and the execution of the experiments. For the theoretical perspective, the cognitive mechanism is not comprehensively studied. As is know, cognition involves a lot of complex factors, not only one's intelligence and nerves but also contextual and social factors. The thesis only refers to those factors which are more accurate in a scientific study but a little ideal from the actual situation. We expect a larger-scaled scientific view on the problem where more cognitive matters and mechanism can be included.

\section{ACKNOWLEDGMENT}

First of all, my heartfelt thanks go to Prof. Wang Lunan, my supervisor, who has helped so much at every step of this thesis. I have frequently consulted him on various theoretical and technical issues as well as the research methodology and philosophy. He has never hesitated to give me suggestions and encouragement. He has often urged me to improve the thesis. Despite these, I would like to claim that any mistake and fault in this thesis will be solely due to my own insufficiency of academy. I would like to thank my family, who have supported me to accomplish this research with their love and care.

\section{REFERENCES}

[1] Anderson, A. \& Lynch, T. (1988). Listening. Oxford: Oxford University Press.

[2] Anderson, J.R. (1985). Cognitive Psychology and Its Implications ( $2^{\text {nd }}$ edition.). New York: W.H. Freeman.

[3] Anderson, R.C. (1978). Schema-directed processes in language comprehension. In Lesgold, A.M., Pellegrino, M.J., Fokkema, S.D., and R. Glaser, R., (Ed.s.). Cognitive Psychology and Instruction. New York: Plenum Press.

[4] Berk. L.M. (1999). English Syntax: From Word to Discourse. New York.

[5] Carrell, P.L.\& Eisterhold, J.C. (1983). Schema theory and ESL reading pedagogy. (pp.553-573). TESOL Quarterly. 17.

[6] Carrell, P.L. (1984). The effects of rhetorical organization on ESL readers. (pp.442-469). TESOL Quarterly. 18.

[7] Gass. (1988). Integrating Research Areas: A Frame Work for Second Language Studies. In. Applied Linguistics.

[8] Gass. (1997). Input, Interaction and the Second Language Learner. Mahwah, NJ: Lawrence Erlbaum Associates

[9] Gass \& Selinker. (2001). Second Language Acquisition: An Introductory Course. Mahwah, NJ: Lawrence Erlbaum Associates.

[10] Fowler. H.W. (1926). A Dictionary of Modern English Usage. Oxford.

[11] Jespersen. (1905). Growth and Structure of the English Language. Leipzig.

[12] Jesperson. (1933). Essentials of English Grammar. London.

[13] Jespersen. (1984). The philosophy of Grammar. London.

[14] Krashen. (1982). Principles and Practice in Second Language Acquisition. Oxford: Pergamon.

[15] Krashen. (1985). The Input Hypothesis: Issues and Implications. London: Longman.

[16] Krashen. (1987). Principles and Practices in Second Language Acquisition. New York: Prentice-Hall International.

[17] Krashen. (1989). We Acquire Vocabulary and Spelling by Reading: Additional Evidence for the Input Hypothesis. Modern Language Journal. 
[18] Levelt. (1989). Speaking: from Intention to Articulation. Cambridge, MA: The MIT Press

[19] McLaughlin. (1987). Theories of Second-language Learning. London: Edward Arnold.

[20] Palmer. (1974). The English Verb. London.

[21] Pica et al. (1989). Comprehensible Output as an Outcome of Linguistic Demands on the Learner. Studies in Second Language Acquisition.

[22] Quirk et al. (1972). A Grammar of Contemporary English. Longman.

[23] Quirk. (1974). A University Grammar of English. Longman.

[24] Quirk et al. (1985). A Comprehensive Grammar of the English Language. London.

[25] Richards. J.C et al. (2000). Longman Dictionary of Language Teaching \& Applied Linguistics. Longman.

[26] Sternberg, R.J. (1997). Intelligence. Information processing, and analogical reasoning: The componential analysis of human abilities. Hillsdale. New Jersey: Erlbaum.

[27] Swain. (1985). Communicative Competence: Some Roles of Comprehensible Input and Comprehensible Output in Its Development. In S. Gass \& C. Madden (eds.), Input in Second Language Acquisition. Rowley: Newbury House.

[28] Swain. (1995). Three Functions of Output in Second Language Learning. In G. Cook \& B. Seidlhofer (eds.), Principle and Practice in Applied Linguistics. Oxford: Oxford University Press.

[29] Swain \& Lapkin. (1995). Problems in Output and the Cognitive Processes They Generate: A Step towards Second Language Learning. Applied Linguistics.

[30] Zhang Daozhen. (2002). Practical English Grammar. Beijing: Commercial Press.

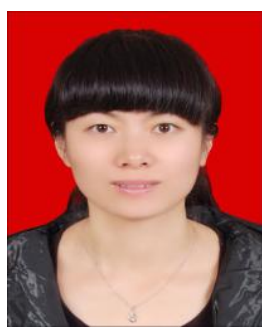

Ting Zhang, born in Xichang City, Sichuan Province, China. May 28, 1979. Graduating from Sichuan International Studies University (SISU), Chongqing City, China. Acquiring the Master Degree of Literature in 2009. Now Majoring in Linguistics.

She works in Sichuan Agriculture University (SAU) now as a Lecturer and used to be a part-time teacher in SISU. She has published 3 essays within the recent 6 years. Namely:

Zhang Ting (2006). How to Facilitate the Knowledge of Phonology for English Learners. (pp.166). Contemporary Academic Research. 3.

Zhang Ting (2006). The Relationship Between the Basic Linguistics Study and the Basic Teaching of English in Chinese Colleges . (pp.319). Contemporary Academic Research. 3.

Zhang Ting (2008). Analysis on the Reasons for Mistakes in the Oral English Acquisition. (pp.153) Journal of Sichuan International Studies University. 